\title{
Lo que sabemos y lo que no sabemos.
}

\author{
What we know and what we do not know.
}

Roberto J. Beltrán ${ }^{1, a}$

Los profesores de odontología estamos acostumbrados a transmitir información teórica y a adiestrar a los alumnos en procedimientos técnicos de laboratorio y de clínica (y no lo hacemos tan mal, nuestros discípulos ejercen el arte con bastante éxito). Es decir, sabemos actuar sobre los dominios cognitivo y psicomotor de la clasificación de Bloom y colaboradores. En la misma clasificación se encuentra el dominio afectivo, para el cual no tenemos una metodología de enseñanza-aprendizaje-evaluación que nos permita seguir con fidelidadel comportamiento del alumno en ese dominio. Por nuestra parte, hemos propuesto la inclusión de un nuevo dominio, que hemos llamado DOMINIO VOLITIVO.

Para este dominio tampoco tenemos métodos demostrados como eficaces para estimular en el alumno la voluntad de rendir en su aprendizaje y en su práctica, al máximo de sus posibilidades y dotes personales. Recordemos que lo que hace el proceso de comunicación docente/alumno es abrir las puertas para que las potencialidades del alumno pueden desarrollarse al máximo, potencialidades que permanecen latentes desde los primeros momentos de la vida. Una pobre experiencia educativa sofocará esa llama de inteligencia, afectividad, destreza y tesón. El profesional será un repetidor mecánico de procedimientos.

La carencia de metodologías apropiadas para la enseñanza-aprendizaje-evaluación de los dominios afectivo y volitivo, nos pone en la situación de tener que aceptar que el desarrollo de esas potencialidades del alumno queda librado al azar. He aquí un campo de la educación que requiere mucha investigación.

En trabajos previos hemos demostrado que el dominio volitivo no puede estar incluido en el dominio afectivo. Definimos el dominio volitivo como la capacidad que desarrolla el alumno para empeñarse en el logro del mejor resultado en sus aprendizajes y trabajos. Decimos que es un dominio del aprendizaje porque es algo que se puede enseñar y aprender, más allá de las dotes personales de cada quien.

Hemos sugerido que una forma de estimular este alto grado de dedicación es mediante un minucioso proceso de aprendizaje que incluya demostraciones excelentes por parte de los instructores y de material fílmico,

Facultad de Estomatología. Universidad Peruana Cayetano Heredia. Lima, Perú.

a Profesor Emérito. 
aprendizaje global y lineal, el primero para actuar con conocimiento del porqué y el para qué de la acción y el segundo para respetar una secuencia de actos perfectamente delimitados y ordenados.

Sugerimos que la vigilancia del trabajo del alumno por parte del instructor debe ser inmediata tanto en el tiempo como en el espacio. Esa vigilancia de los aprendizajes hará posible la intervención oportuna del instructor para corregir a tiempo y exigir las rectificaciones que se precise. Creemos que nada más perjudicial para el alumno es que se le deje proceder sin reconocer sus errores en el momento que los comete para rectificarlos. Pensamos que este tipo de exigencia es la clave del éxito en enseñanza-aprendizaje-evaluación del dominio volitivo. Reconocemos que estas apreciaciones deben ser corroboradas mediante investigaciones minuciosas que nos proporcionen las certezas que requerimos como instructores clínicos y de laboratorio. Es un gran reto para los profesores que quieran contribuir a la formación integral de sus alumnos. En síntesis, se trata de desarrollar metodologías que aseguren el aprendizaje en los dominios afectivo y volitivo.

Explorando los recursos disponibles pensamos, por ejemplo, que el trabajo de campo en contacto con las necesidades de salud de las comunidades menesterosas puede facilitar el crecimiento y desarrollo de la sensibilidad humana y social de los alumnos. Este desarrollo de la sensibilidad permitirá que la conducta del alumno frente a sus pacientes en la clínica universitaria sea la correcta en términos de empatía y respeto. La atención del dolor o de otra emergencia requiere trato especial, cualquiera que sea la condición social o cultural del paciente.

Por su parte el desarrollo del placer que ocasiona el mejor logro de una tarea, estimulará en el alumno el empeño por alcanzar excelencia. Si el alumno no siente placer con los resultados de su trabajo, puede querer decir que no ha desarrollado su dominio volitivo.

Es función de la entidad educativa estimular en los profesores el interés por encontrar las mejores experiencias que faciliten el desarrollo de las facultades de sus alumnos. En verdad, todo profesor debe ser un investigador de su acción educativa.

\section{CORRESPONDENCIA}

Prof. Roberto J. Beltrán

robertobeltranneira@gmail.com

Recibido : 18-04-2012

Aceptado: 13-07-2012 